\title{
Pelatihan Handicraft Berbasis Logic Exploxer Meningkatkan Kemampuan Hard Skill
}

\author{
Budi Kurniawan ${ }^{1}$, Elisabeth Ernawaty Fernandes ${ }^{2}$, Karima Tunisa Palla ${ }^{3}$ iD \\ ${ }^{1,2.3}$ Program Studi Pendidikan Guru Sekolah Dasar Universitas Muhammadiyah Kupang, Indonesia. \\ *Corresponding author: kurniawanbudi012@gmail.com
}

\begin{abstract}
Abstrak
Tujuan pengabdian masyarakat ini meningkatkan kemampuan hard skill peserta didik Sekolah Dasar (SD) dengan pengadaan pelatihan edukasi hard skill melalui handicraft berbasis logic exploxer. Pengabdian dilakukan dengan beberapa kegiatan diantaranya ialah pengolaan limbah sampah plastik menjadi kerajianan tangan dan pengolaan batu pantai yang beragam bentuk dan warna menjadi kerajinan tangan. Metode pelaksanaan yang digunakan dalam kegiatan pengabdian masyarakat ini dibagi menjadi empat tahap diantaranya (1) observasi awal wilayah kegiatan, (2) pemetaan masalah, (3) sosialisasi kegiatan, dan (4) pelaksanaan pelatihan dengan melibatkan masyarakat, mahasiswa, dan dosen. Hasil pelatihan menunjukkan bahwa melalui pelatihan handicraft berbasis logic exploxer mampu meningkatan pengetahuan serta pemanfaatan limbah sampah plastik dan batu pantai yang beragam warna dan bentuknya, menjadi aneka kerajinan tangan (handicraft) bernilai ekonomis berupa metodemetode yang disampaikan melalui jasa pelatihan. Selain itu, mampu meningkatkan pemahaman dan pengetahuan tentang manajemen kewirausahaan melalui jasa pelatihan. Luaran dari kegiatan ini adalah pemahaman masyarakat dan peserta didik tentang pengolahan sampah plastik dan batu berwarna serta kemampuan mengembangkan hard skill peserta didik.
\end{abstract}

Kata Kunci: Handicraft, Hard skills, Logic Exploxer

\section{Abstract}

The purpose of this community service is to improve the hard skills of elementary school (SD) students by providing hard skill education training through handicrafts based on logic explorers. The service is carried out with several activities including processing plastic waste into handicrafts and processing beach stones of various shapes and colors into handicrafts. The implementation method used in this community service activity is divided into four stages including (1) initial observation of the activity area, (2) problem mapping, (3) activity socialization, and (4) training implementation by involving the community, students, and lecturers. The results of the training showed that through logic explorer-based handicraft training, they were able to increase knowledge and use of plastic waste and beach stones of various colors and shapes, into various handicrafts (handicrafts) of economic value in the form of methods delivered through training services. In addition, being able to increase understanding and knowledge of entrepreneurial management through training services. The output of this activity is the understanding of the community and students about processing plastic waste and colored stones and the ability to develop students' hard skills.

Keywords: Handicraft, Hard skills, Logic Exploxer

\section{INTRODUCTION}

Kerajinan tangan (handicraft) adalah menciptakan suatu produk atau barang yang dilakukan oleh tangan dan memiliki fungsi pakai atau keindahan sehingga memiliki nilai jual (Nurlaily et al., 2017; Riyanto, 2015; Sitorus \& Padwa, 2020). Fungsi pakai adalah suatu kerajinan yang mengutamakan kegunaan dari karya tersebut sehingga keindahan hanya sebagai penarik saja. Sementara itu, fungsi keindahan adalah suatu kerajinan yang sangat mengutamakan keindahan tanpa memperhatikan kegunaan dari karya tersebut dan hanya dapat dinikmati dengan mata (Rosyida \& Subiyati, 2018; Salma et al., 2015). Desa Kolbano merupakan salah satu desa yang berada di Kecamatan Kolbano Kabupaten Timor Tengah Selatan (TTS) yang memiliki penduduk 700 Kepala Keluarga. Desa ini memliki pantai yang dinamakan pantai Kolbano. Pantai Kolbano merupakan salah satu pantai yang terletak di

$\begin{array}{ll}\text { History: } & \\ \text { Received } & \text { : July 26, } 2021 \\ \text { Revised } & \text { : July 28, 2021 } \\ \text { Accepted } & \text { : August 16, } 2021 \\ \text { Published } & \text { : August 25, } 2021\end{array}$


Kabupaten TTS, Provinsi Nusa Tenggara Timur (NTT). Pantai Kolbano memliki landscape yang sangat indah. Keunikan Pantai Kolbano terdapat pada hamparan batu yang berwarna merah, hijau, kuning, hitam, dan pencampuran warna yang lain. Batu ornamen berbentuk lonjong, pipih, membundar tanggung sampai bundar di pantai Kolbano merupakan hasil pelapukan dari batu yang lebih tua. Batuan ornamen ini perkiran berasal dari Formasi Ofu (Tko) dan Formasi Wailuli (Jw). Pantai Kolbano memiliki ombak yang cukup tenang sehingga sangat cocok untuk digunakan sebagai kawasan wisata bahari. Pantai Kolbano merupakan tempat sempurna untuk melihat matahari terbit dan melihat langit memerah saat senja. Keindahan pantai kolbano sudah menjadi salah satu destinasi unggulan di daerah TTS, sehingga menarik perhatian wisatawan untuk datang berkunjung ke pantai Kolbano.

Pengolahan pantai Kolbano masih belum baik hal ini dikarenakan banyak permasalahan yang timbul seperti banyaknya masyarakat sekitar yang belum terlibat aktif dalam kegiatan wisata di pantai Kolbano. Tingkat kesadaran masyarakat pedesaan terhadap potensi ekonomi lokal, khususnya di bidang parawisata masih tergolong rendah. Keterlibatan masyarakat lokal dan stakeholder menjadi faktor penting dalam pengembangan kawasan wisata. Potensi alam yang dipadukan dengan keterlibatan komunitas lokal dapat membuat aktivitas ekonomi lokal meningkat secara drastic (Anggi et al., 2020; Nurkhalis et al., 2018; Wattimena, 2016). Keadaan pantai Kolbano belum terawat dengan baik. Banyak sampah yang berserakan disekitar pantai, yang disebabkan oleh para pengunjung yang membuang sampah tidak pada tempatnya serta kurangnya kreativitas masyarakat dalam mendaur ulang limbah sampah. Sampah akan menumpuk terus menerus apabila tidak dikelola dengan baik. Apalagi sampah yang menumpuk lama kelamaan akan menjadi padat dan berserakan, sehingga dapat mengganggu suasana sehingga lingkungan menjadi kumuh dan kotor (Agus et al., 2019; Hamsa \& Sulaiman, 2021; et al., 2021).

Tantangan khusus bagi pengelola tempat destinasi, dalam memberikan buadaya literasi akan pentingnya menjaga lingkungan di sekitar area Kolbano salah satunya dengan memanfaatkan sampah plastik menjadi suatu kerajinan tangan (handicraft). banyak Potensi yang harus digali, begitu besar perlu adanya perhatian lebih dalam meningkatkan keterampilan Sumber Daya Manusia (SDM) dan pemanfaatan Sumber Daya Alam (SDA) khususnya di Kecamatan Kolbano, Kabupaten Timor Tengah Selatan (TTS). Beberapa kegiatan pengabdian masyarakat telah sukses dilakukan dengan melakukan pelatihan pembuatan kerajinan tangan dengan memanfaatkan sampah plastik (Agus et al., 2019; Hamsa \& Sulaiman, 2021; et al., 2021). Kemudian ada juga pelatihan pengabdian dengan kegiatan pengembangan Desa Wisata (Hudayana et al., 2019; Trisnawati et al., 2018).

\section{MATERIALS AND METHODS}

Pengabdian ini dilaksanakan pada area Pantai Kolbano, Desa Kolbano, Kecamatan Kolbano, Kabupaten TTS, Provinsi NTT. Waktu pelaksanaannya ini pada bulan Juni 2021. Kerjasama kemitraan dilakukan bersama dengan Kepala Desa Kolabano, Mayarakat, dan Perguruan Tinggi (PT) dalam hal ini pada Program Studi Pendidikan Guru Sekolah Dasar (PGSD), Universitas Muhammadiyah Kupang untuk mendukung kegiatan edukasi kemampuan hard skill melalui handicraft berbasis logic exploxer di Desa Kolbano, Kecamatan Kolbano, Kabupaten TTS, Provinsi NTT. Observasi lapangan dilakukan dengan melakukan survei langsung maupun diskusi dengan peserta didik dan masyarakat untuk mengetahui permasalahan yang dihadapi oleh peserta didik. Perlu adanya sosialisasi terhadap peserta didik dan masyarakat sekitar dalam pemanfaatan limbah sampah plastik dan batu pantai yang beragam bentuk dan warna, sehingga peserta didik dan masyarakat paham dan bersedia bekerja sama dan menerima metode-metode yang akan disampaikan berupa pelatihan. Perlu adanya 
pelatihan bagi peserta didik untuk dapat meningkatkan pemahaman edukasi keterampilan hard skill melalui handicraft berbasis logic exploxer di Desa Kolbano, Kecamatan Kolbano, Kabupaten TTS, Provinsi NTT. Adapun kerangka pemikiran kegiatan Pengabdian Masyarakat ini disajikan dalam bentuk flowchart pada Gambar 1.

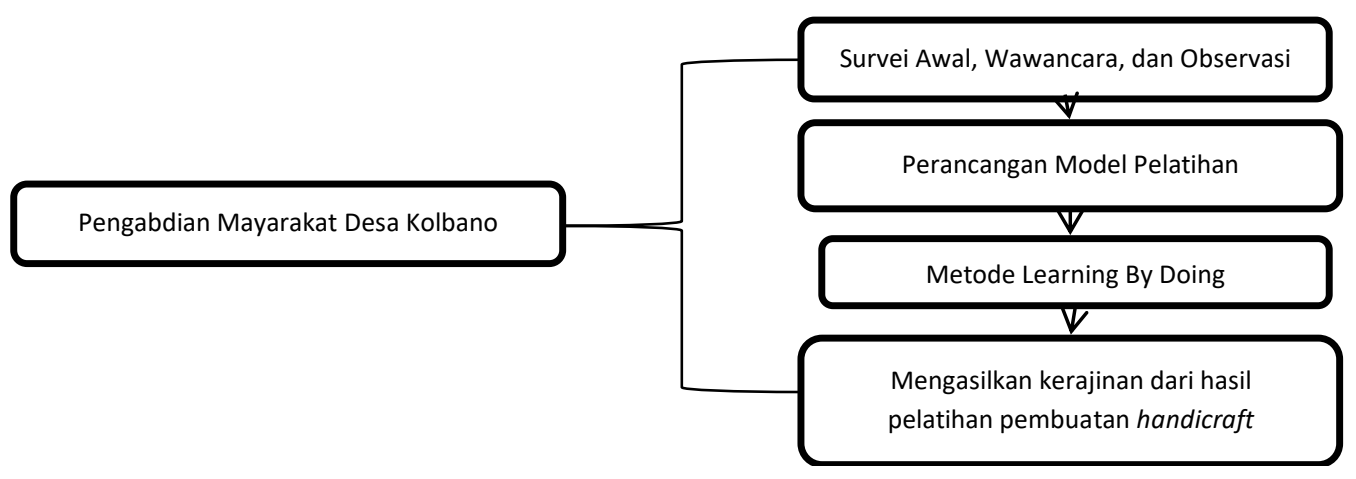

Gambar 1. Kerangka Pemikiran.

\section{RESULTS AND DISCUSSION}

\section{Hasil}

Kegiatan pengabdian masyarakat dengan tema Edukasi Hardskill melalui Handicraft Berbasis Logic Exploxer di Desa Kolbano, Kecamatan Kolbano, Kabupaten TTS, Provinsi NTT diawali dengan sebuah kata sambutan dari salah seorang tokoh masyarakat Desa Kolbano sekaligus membuka kegiatan tersebut. Selanjutnya Tim Pelaksana kegiatan pengabdian masyarakat mengucapkan terima kasih atas sambutan dan diberikannya izin melaksanakan pengabdian di Desa Kolbano. Dalam pelaksanaan kegiatan pelatihan ini strategi yang digunakan adalah dengan cara memberikan sosialisasi dan pendampingan secara tahap demi tahap dimulai dari melakukan survei awal sampai ketahap cara membuat batu pantai dan limbah sampah plastik menjadi kerajinan tangan. Langkah-langkah pelaksanaannya diantaranya adalah 1) melakukan survei awal, wawancara dengan masyarakat sekitar dan observasi melihat limbah sampah plastik yang berserakan di sekitar pantai Kolbano; 2) perancangan model pelatihan yang akan dilaksanakan dengan menentukan apa saja yang menjadi kebutuhan untuk mendukung kegiatan peserta didik, dengan berdasarkan informasi, seleksi konsep, evaluasi, menentukan spesifikasi alat dan bahan yang digunakan, serta analisa biaya operasional; 3) metode pendekatan yang dilakukan adalah metode learning by doing. Metode ini proses pelatihan dilaksanakan di tepi pantai Kolbano, hal ini dilakukan bersama masyarakat sekitar. Metode partisipatif, yang diterapkan dalam proses pelatihan dan pendampingan ini, keterlibatan pasrtisipasi dari peserta didik dan masyarakat secara langsung dalam pengaplikasiannya. Dari pelaksanaan pelatihan edukasi hard skill melalui handicraft berbasis logic exploxer di Desa Kolbano, Kecamatan Kolbano, Kabupaten TTS, dengan melibatkan peserta didik untuk dilatih keterampilan dan hard skill menghasilkan beberapa keterampilan. Hasil keterampilan dapat dilihat pada Gambar 2. 


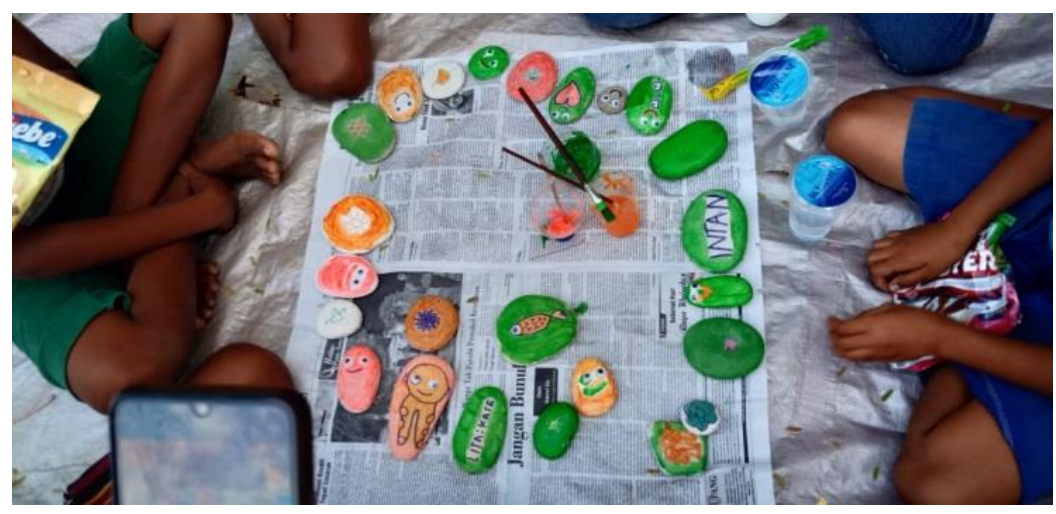

Gambar 2. Hasil pelatihan keterampilan

\section{Pembahasan}

Berdasarkan hasil anlisis kebutuhan masyarakat di daerah wisata Pantai Kolbano banyak hal yang ditemukan. Masalah yang pertama adalah lingkungan pariwisata yang belum di kelolah dengan baik hal ini di tunjukan degan banyak sekali lopo yang tidak terawat serta tempat kebersihan yang belum disediakan, di samping itu juga masalah kedua yang sangat menganggu bagi pegunjung tempat wisata tersebut adalah banyaknya sampah plastik yang berserakan di tempat wisata. Oleh karena itu, dengan dilakukannya sosialisasi akan pentingnya menjaga kebersihan dan dampak yang diakibatkan oleh limbah sampah plastik sangatlah berbahaya bagi ekosistem yang ada di daerah wisata Kolbano. Proses sosialisasi dikembangkan lagi menjadi sebuah prosedur pelatihan yang dimana mayarakat diberikan materi bagaimana mampu mengolah limbahan organik menjadi suatu kerajinan tangan atau handicraft. Kebutuhan perta didik di masa pendemi Covid-19 banyak kendala dalam hal melatih keterampilan peserta didik sehingga pelatihan pembuatan handicraft sangat dibutuhkan untuk mengetahui langkah-langkah dalam megelolah kerajinan tangan.

Langkah utama yang dilakukan agar menghasilkan sebuah kerajinan tangan yaitu melakukan sosialisasi dengan masyarakat karena hal itu dapat mempererat hubungan baik antara masyarakatnya dan kita dapat memperoleh informasi mengenai lingkungan tersebut. Selanjutnya tujuan mengadakan sosialisasi dan pelatihan terlebih dahulu agar memudahkan peserta didik untuk memahami proses pembuatan kerajinan tangan yang ada di Desa Kolbano. Peserta didik dapat memahami arti dan fungsi dari kerajinan tangan, agar setiap anggota masyarakat dapat mengetahui nilai-nilai dari kegiatan dan kegiatan tersebut dapat berjalan dengan baik. Dalam kegiatan ini peserta didik dibagi menjadi beberapa kelompok agar proses pengerjaannya lebih efektif dan masing-masing kelompok didampingi oleh beberapa mahasiswa untuk mengarahkan proses pembuatan kerajinan tangan yang akan dikerjakan oleh peserta didik.

Kerajinan tangan adalah kegiatan yang berhubungan dengan menciptakan suatu barang atau produk yang dihasilkan dari keterampilan tangan atau kegiatan yang berhubungan dengan menghasilkan suatu barang (Azis, 2017; Kristinae, 2018; Pasaribu et al., 2017). Kerajinan tangan yang bernilai ekonomis adalah kerajinan yang dibuat berupa barang atau produk yang mempunyai kuantitas terbaik dengan pemilihan bahan seminimal mungkin (Otaya et al., 2019; Putra et al., 2019; et al., 2015). Dalam pelaksanaan pelatihan edukasi kemampuan hard skill melalui handicraft berbasis logic exploxer, peserta didik dibimbing untuk membuat sebuah kerajinan tangan dengan bahan dasar adalah batu pantai dan limbah sampah plastik. Dalam proses pembuatan batu pantai ini mahasiswa mengarahkan peserta didik untuk memilih beberapa batu yang ada di tepi pantai sesuai dengan ukuran dan bentuk yang mereka inginkan. Lalu batu pantai tersebut dicuci bersih terlebih dahulu kemudian didiamakan beberapa menit 
hingga kering. Setelah itu, mahasiswa mengarahkan peserta didik untuk mengaduk cat air di dalam sebuah wadah dengan warna yang didinginkan kemudian diterapkan pada sisi batu, lalu batu yang telah di cat, didiamkan di bawa terik matahari hingga kering. Setelah batunya sudah kering, peserta didik menggambar sesuatu seperti hewan dan tumbuhan serta menggambar sekolah beserta jenis sarana dan prasarana sekolah atau menggambar sesuai dengan imajinasi mereka. Beberapa dari mereka menggambar pohon, bunga, kupu-kupu, laba-laba, kelinci, bendera, bola, kursi, meja, ikan, bintang, bulan, emoji, serta menulis nama mereka sendiri. Hasil kegiatan pengabdian masyarakat di Desa Kolbano banyak memberikan manfaat kepada masyarakat dan peserta didik terutama melatih hard skill peserta didik.

\section{CONCLUSION}

Adanya kegiatan pengabdian masyarakat edukasi kemampuan hard skill melalui handicraft berbasis logic exploxer mampu meningkatan pengetahuan serta pemanfaatan limbah sampah plastik dan batu pantai yang beragam warna dan bentuknya, menjadi aneka kerajinan tangan (handicraft) bernilai ekonomis berupa metode-metode yang disampaikan melalui jasa pelatihan. Selain itu, mampu meningkatkan pemahaman dan pengetahuan tentang manajemen kewirausahaan melalui jasa pelatihan.

\section{REFERENCES}

Agus, R. N., Oktaviyanthi, R., \& Sholahudin, U. (2019). 3R: Suatu Alternatif Pengolahan Sampah Rumah Tangga. Kaibon Abhinaya: Jurnal Pengabdian Masyarakat, 1(2), 72. https://doi.org/10.30656/ka.v1i2.1538.

Anggi, M., Pramitasari, D., \& Marcillia, S. R. (2020). Citra Ubud Bali Berdasarkan Peta Kognisi Masyarakat. Langkau Betang: Jurnal Arsitektur, 7(1), 25. https://doi.org/10.26418/lantang.v7i1.34859.

Azis, B. (2017). Kearifan Lokal Masyarakat Kampung Wisata Kerajinan Tangan di Dusun Rejoso Kota Batu. Local Wisdom: Jurnal Ilmiah Kajian Kearifan Lokal, 9(1). https://doi.org/10.26905/lw.v9i1.1862.

Basran, M. A., \& Burhanuddin, B. (2015). Museum Tembikar Dan Kerajinan Tangan Dengan Pendekatan Bangunan Pintar Di Makassar. Nature: National Academic Journal of Architecture, 2(1), 86-96. https://doi.org/10.24252/nature.v2ila8.

Hamsa, A., \& Sulaiman, R. (2021). Penyuluhan Pengolahan Sampah Pada Anak di Komunitas Youth Sikolata. Madaniya, 2(3), 313-322. https://doi.org/10.53696/27214834.96.

Hudayana, B., made Kutanegara, P., Setiadi, S., Indiyanto, A., Fauzanafi, Z., Nugraheni, M. D. F., Sushartami, W., \& Yusuf, M. (2019). Participatory Rural Appraisal (PRA) untuk Pengembangan Desa Wisata di Pedukuhan Pucung, Desa Wukirsari, Bantul. Bakti Budaya, 2(2), 3-16.

Kristinae, V. (2018). Pengaruh Produk, Harga dan Promosi Terhadap Minat Konsumen Untuk Melakukan Pembelian Kerajinan Tangan Rotan. Eksis: Jurnal Riset Ekonomi Dan Bisnis, 13(1), 25-30. https://doi.org/10.26533/eksis.v13i1.154.

Mariam, I., Latianingsih, N., \& Danaryani, S. (2021). Optimalisasi Pengelolaan dan Pengolahan Sampah Terpadu dalam Upaya Meningkatkan Kualitas Lingkungan Masyarakat Desa Ciampea Udik Kabupaten Bogor. Bhakti Persada, 7(1), 24-31. https://doi.org/10.31940/bp.v7i1.2431.

Nurkhalis, N., Arief, H., \& Sunarminto, T. (2018). Analisis Stakeholders Dalam Pengembangan Ekowisata di Hutan Adat Ammatoa Kajang Sulawesi Selatan. Jurnal Pariwisata, 5(2), 107-119. https://doi.org/10.31311/par.v5i2.3811.

Nurlaily, A. A., Irianto, I., \& Sunarno, E. (2017). Rancang Bangun Alat Pengering Eceng 
Gondok Untuk Bahan Kerajinan Tangan (Menggunakan Metode Tuning Controller Chien Regulator I dan Chien Servo I). Jurnal Teknologi Dan Manajemen Informatika, 3(2). https://doi.org/10.26905/jtmi.v3i2.1522.

Otaya, L. G., Tjabolo, S. A., \& Husain, R. T. (2019). Analisis kebutuhan pemberdayaan ibu rumah tangga miskin melalui usaha kerajinan tangan khas Gorontalo "Mohalamu Tiohu." JPPM (Jurnal Pendidikan Dan Pemberdayaan Masyarakat), 6(1), 59-75. https://doi.org/10.21831/jppm.v6i1.21736.

Pasaribu, H., Rafi, C., \& Khairawati, K. (2017). Persepsi Generasi Y Terhadap Kerajinan Tangan Daerah. Jurnal Ilmiah Manajemen \& Bisnis, 18(2), 212. https://doi.org/10.30596/jimb.v18i2.1520.

Putra, I. M. S., Raharja, I. M. S., Sutramiani, N. P., \& Susila, A. A. N. H. (2019). Pengenalan E-Commerce pada Pengerajin Tangan di Desa Sambirenteng Kecamatan Tejakula Kabupaten Buleleng. Buletin Udayana Mengabdi, 18(3), 159-164. https://doi.org/10.24843/bum.2019.v18.i03.p26.

Riyanto, A. A. (2015). Keterampilan Berwirausaha Bagi Perempuan Dalam Upaya Peningkatan Kesejahteraan Keluarga. Jurnal Empowerment, 4(2), 50-85. https://doi.org/https://doi.org/10.22460/empowerment.v4i2p50-62.566.

Rosyida, A., \& Subiyati, S. (2018). Pemanfaatan Limbah Serutan Kayu Nangka (Artocarpus Heterophyllus) Untuk Pewarnaan Kain Sutera Utilization of Jackfruit Wood (Artocarpus heterophyllus) for Coloring Silk Fabrics. Dinamika Kerajinan Dan Batik, 35(2). https://doi.org/https://doi.org/10.22322/dkb.v35i2.4301.

Salma, I. R., Wibowo, A. A., \& Satria, Y. (2015). Kopi Dan Kakao Dalam Kreasi Motif Batik Khas Jember Coffee and Cocoa in Typical Batik Motif Creation of Jember. Dinamika Kerajinan Dan Batik, 32(2). https://doi.org/https://doi.org/10.22322/dkb.v32i2.1362.

Sitorus, F. R. P. P., \& Padwa, A. A. M. (2020). Berkreasi Membuat Kerajinan Tangan Sekaligus Mengurangi Sampah Botol Plastik. Jurnal Pengabdian Dharma Laksana, $3(1)$. .

Trisnawati, A. E., Haryono, H., \& Wardoyo, C. (2018). Pengembangan Desa Wisata dan Pemberdayaan Masyarakat Berbasis Potensi Lokal. Jurnal Pendidikan: Teori, Penelitian, Dan Pengembangan, 3(1), 29-33. https://doi.org/http://dx.doi.org/10.17977/jptpp.v3i1.10356.

Wattimena, L. (2016). Wisata Kampung Adat Huaulu di Pulau Seram, Maluku. Kapata Arkeologi, 11(1), 67. https://doi.org/10.24832/kapata.v11i1.282. 